\title{
Salmonella Carrier State in Ostriches and Epizootological Situation in Ararat Region
}

\author{
M.A. Sargsyan, H.S. Balasanyan, G.R. Tovmasyan \\ Armenian National Agrarian University \\ mariam.sargsyan.1960@mail.ru, nanar.balasanyan.s@gmail.com, gohartovmasyan74@mail.ru
}

\section{A RT I CLE IN F O}

Keywords:

ostrich,

salmonellas,

epizootology,

egg,

salmonella carrier state,

Salmonellosis

\begin{abstract}
A B S T R A C T
Salmonella carrier state of ostriches and epizootological conditions have been studied and identified for the first time in Ararat region of the Republic of Armenia.

As an endemic infectious disease, Salmonellosis has caused significant economic damage to ostrich farms. Bacteria carrying birds, caring, feeding and keeping conditions, as well as stressful situations are predisposing factors for the mentioned disease. According to the two-year epizootological investigations, under insecure conditions the indices of infection, death and lethality have made $0.2(20 \%)$, $0.10(10 \%), 0.53(53 \%)$ respectively, while the economic loss amounted to 640000 AMD.
\end{abstract}

\section{Introduction}

Still 5000-6000 years ago humanity carried out investigations and proved that domestication of ostriches highly promotes agricultural development. The world's first ostrich farm was established in 1853, whereas the 20th century is considered to be a period for rapid development of ostrich breeding branch which became common worldwide, including in Armenia (Tarlamazyan and Hambardzumyan, 2004).

Ostriches are the largest birds in the avian world with 3 $\mathrm{m}$ height and 135-150 kg weight. They live in flocks. In Europe their first taming experiments were implemented in the XII century.

Since there are similarities in some properties of ostrich and camel, the former is also called Struthio camelus (Lat. Camelus). The data retrieved from ancient centuries evidence that ostrich meat and brain have specific advantages over the meat products of other animals and poultry (Tarlamazyan and Hambardzumyan, 2004). Great number of ostriches was imported into Armenia in 20122013 (Figure 1).

Salmonellosis is a zoonotic acute infectious disease, towards which agricultural animals, poultry and humans are highly susceptible. The pathogen of this disease was first isolated by the scientists Salmon and Smith in 1855. In 1934, in honor of the scientist Salmon, bacteria of the mentioned group were named Salmonella by the international microbiology society, while the disease itself was called Salmonellosis. The genus of Salmonella 
contains about 2500 serum species, which belong to the family Enterobacteriacae (Bessarabov, 1989, Konopatkin, et al., 1984, Grigoryan, 2002).

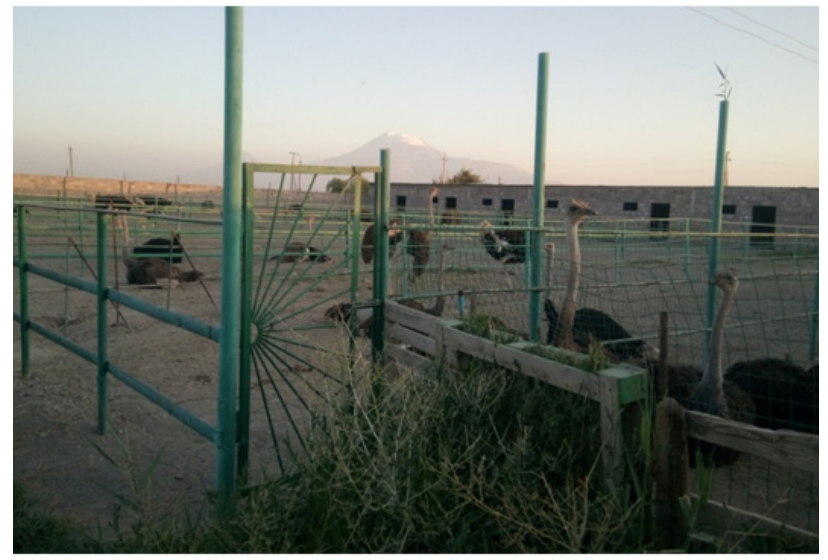

Figure 1. Ostrich farm in Masis city.

Serological diversity of Salmonella ( $S$. galinarum pulorum, S. Typhimurium, S. Enteritidis, S. Heidelberg, S. Montevideo, S. Saintpaul) and its prevalence affects the product quality of poultry and ostrich breeding farms on the whole. It is worth mentioning that the use of the products obtained from Salmonella-affected farms is extremely dangerous for human health (Bakulov, et al., 1986, Bessarabov, et al., 2007). Human infection with food-borne pathogen is directly related to the birds infected with salmonellosis and to the food products contaminated with their pathogens (Grigoryan, 2002, Bessarabov, et al., 2007).

Individual reporters mention that ostriches are also highly susceptible towards the aforementioned serological species (Tarlamazyan and Hambardzumyan, 2004). The disease has been recorded in different countries, including Armenia, and has caused huge amounts of damages to the ostrich farms (Kudryashov and Svyatkovskiy, 2007, Akbarmehr, 2010, Grigoryan, et al., 2012).

Hence, during the case study a task was set up to investigate the salmonella carrier state in ostriches and its prevalence in Ararat region.

\section{Materials and methods}

Ostrich Salmonellosis is an enzootic infectious disease typical of young ostriches which is characterized by its acute and septic developing form, while the adult birds are bacilli carriers with chronic course of the disease (Tarlamazyan and Hambardzumyan, 2004). Environmental factors, feedstuff poor in proteins, lipids, carbohydrates, vitamins and mineral matters (calcium, phosphor salts), as well as zoo-hygienic conditions are predisposing factors for the disease development.

In 2019-2020, for the first time, Salmonella carrier state was studied and epidemiological analyses was conducted in Armenia.

The experiments were conducted in the laboratory of the ANAU Research Center for Veterinary Medicine and Sanitary Examination. Salmonella carrier ostriches were detected through autopsy findings, as well as through microbiological, biological, serological and hematological analyses (Salautin, 1989, Antonov, et al., 1986, Antonov and Blinov, 1971).

The blood, spleen, liver, kidneys, lymph nodes, intestine content, bone marrow, 40-day incubated egg, dead-in-shell (suffocated) chicks, feces and feedstuff of 8 diseased and dead ostriches aged at 3-6 months have served as study objects (Figures 2,3).

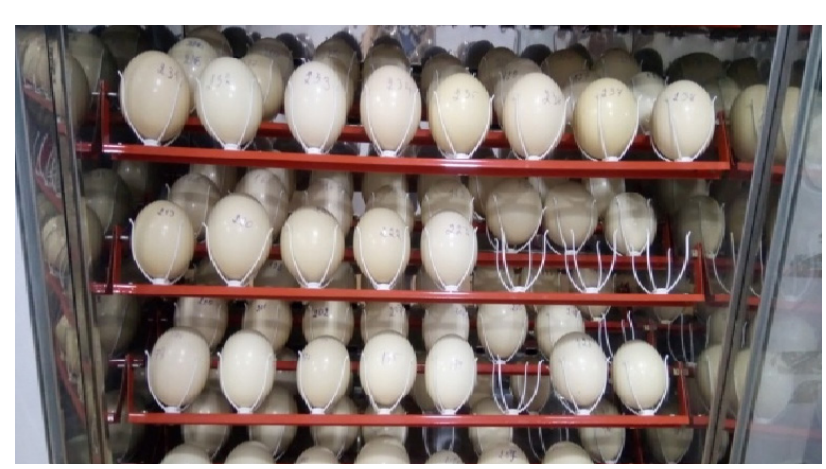

Figure 2. Incubator heating cabinet.

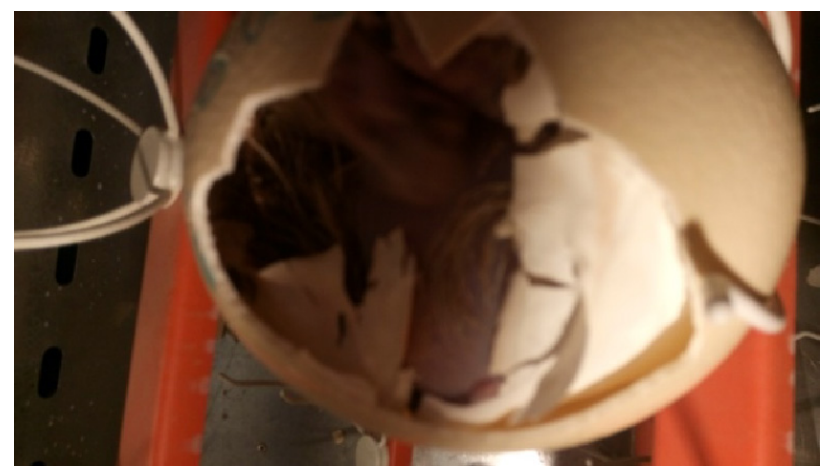

Figure 3. Dead-in-shell chick. 
The infectivity and lethality rate $\left(\mathrm{LD}_{50}\right)$ of the disease pathogen was determined on 12 laboratory white mice with 14-16 g live weight through Reed-Muench method (Syurin, et al., 1984).

The antigen amount (salmonellas) was determined through bacteriological standard, which amounted to $1 \mathrm{ml} / 2 \mathrm{bln}$ microbial bodies (Nurazyan, 1988).

To evaluate the qualitative and quantitative changes in the blood formed elements blood taking was implemented from the inner surface vein of the young ostriches' wings and from the cordis of mice. Morphological and antigenic properties were investigated via microscopic, microbiological and biological methods (Antonov, et al., 1986, Nurazyan, 1988, Borisovich and Kirilov, 1981, Lysak, 2007).

For microbiological research Meat-Pepton Agar (MPA), Meat-Pepton Broth (MPB), Bismuth Sulphite Agar (BSA), Endo Agar (Endo's medium), Levine's Agar and Blood Agar were used (Babich, 1963, Sargsyan and Grigoryan, 2008).

For the development of microbiological cultivars 1:5 suspender was prepared from the concentrated feed samples, while from its extract seeding with the dose of $1.0 \mathrm{ml}$ was conducted in the Bismuth-Sulphite Agar, Endo Agar, MPA and MPB nutrient medium, as well as in milk. The platings were kept at $37^{\circ} \mathrm{C}$ thermostat conditions for 24 hours (Bakulov, et al., 1997).

More than 40 samples of Ostrich feces were taken to study the Salmonella prevalence. The feces sample taken from each ostrich was diluted through physiological solution with the ratio of $1: 10$ and the produced suspender was subjected to centrifugation at 3000-3500 r/m for $10-15$ minutes. After washing the feces sediment for several times smears were prepared and seeding was conducted in the MPA, Bismuth-Sulphite and Endo nutrient mediums. Then the platings were kept at $37^{\circ} \mathrm{C}$ thermostat conditions for 24-48 hours (Bakulov, 1987).

Salmonella sensitivity in vitro conditions towards penicillin, cefazolin, ceftriaxone, sulfanilamide preparations and towards bicillin-3, nitox and synthomycin was investigated.

The epizootological analysis of the investigated territory was conducted per the indices of infection, death, lethality and seasonality, while the economic loss was estimated through the $E l=D_{o} \times C$ - $A l$ formula (Grigoryan, 2002, 2005), which is interpreted in the next section.

\section{Results and discussions}

In recent years the epizootological manifestations of Salmonella have become rather widespread in poultry and ostrich farms of some Armenian regions. It should be mentioned that 75 ostriches (two-toed ostrich) of different age are kept in the ostrich breeding farms of Masis and Edjmiatsin provinces in the Ararat region. In the result of research work monitoring, emaciation, nervousness, labored respiration, conjunctivitis, lacrimation, body tremor, temperature increase, depression, white mucuos foamy diarrhea and lack of appetite was observed in the diseased ostrich chicks. They often fall to the ground with half-open eyes and die within 2-4 days (Figure 5).

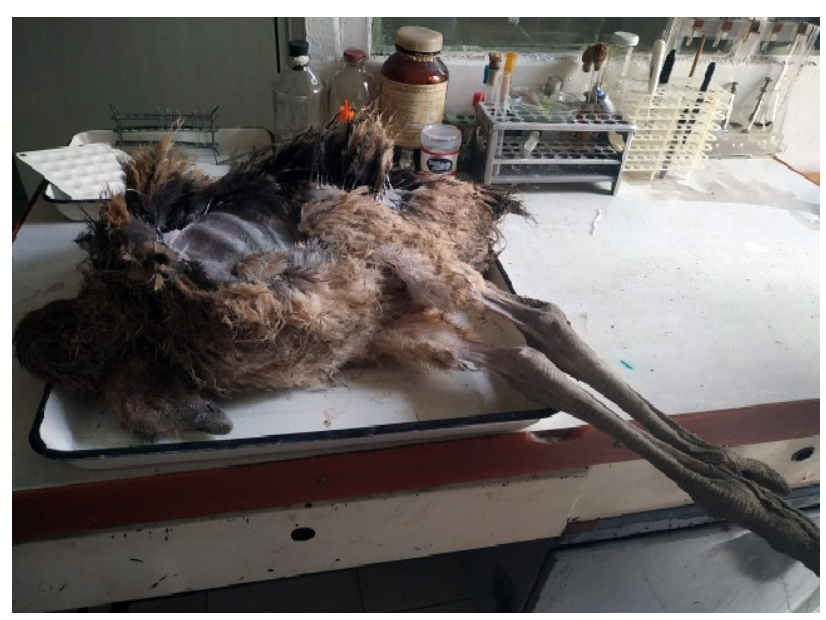

Figure 4. 3-month-old ostriches died of Salmonellosis.

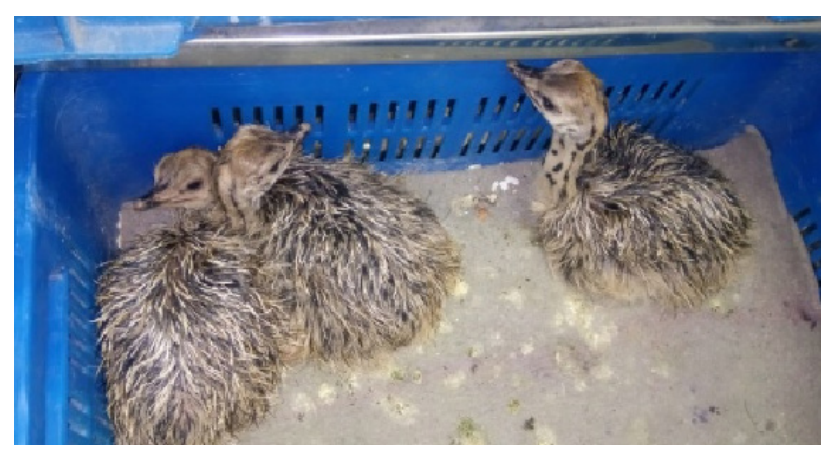

Figure 5. Diseased ostrich chicks.

To find out the cause of death, dissection was carried out. As a result, blood stroke in spleen, lungs, abdominourinary tract, lymph nodes, caecum, small bowel and muscular gastric lining was detected (Figures 4, 6, 7, 8). Besides, the liver was deformed, enlarged and turned into 
yellow-brown color, the kidneys were bruised and swallen, the gallbladder was enlarged and tense filled with bile, while the abdominal cavity was filled with blood serum fluid (Foley, et al., 2008). In adult ostriches increase in body temperature and decline in egg production capacity was recorded.

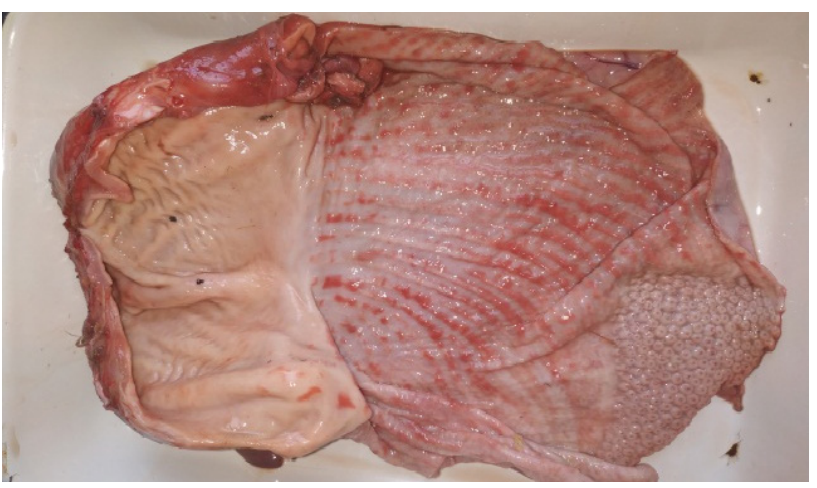

Figure 6. Blood stroke of muscular stomach lining.

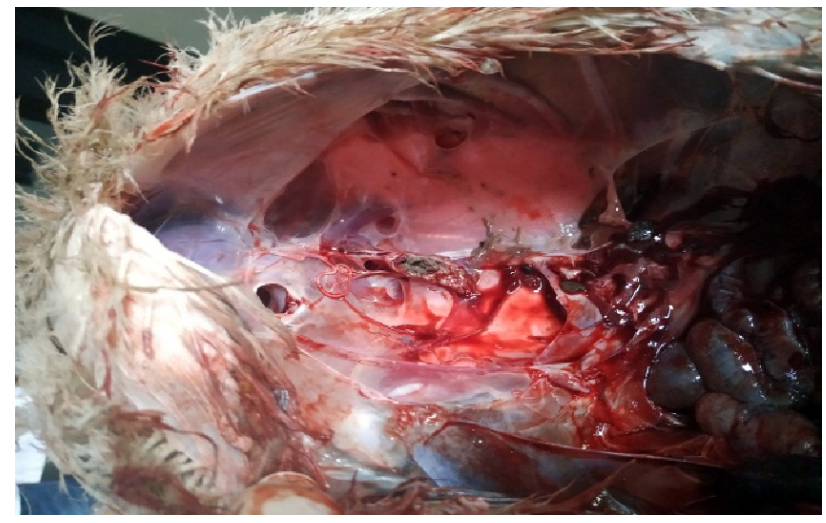

Figure 7. Intestines and lungs infected with Salmonellosis.

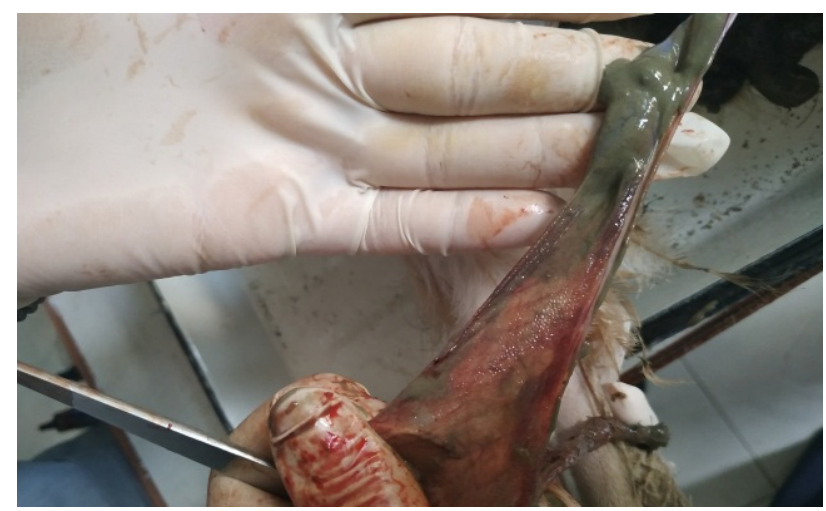

Figure 8. Blood strokes in small intestinal mucosa.
In the result of microscopic investigations gram negative, short, non-sporulating and non-capsulating immobile salmonellas with the size of 0.7-2.5 $\mu \mathrm{m}$ have been detected in the imprint smears prepared from the pathological substances, while in the Meat-Peptone-Blood Agar hemolyzed circle around the microbial colonies has been observed. In the Bismuth-Sulphite Agar black and round colonies with smooth edges have been found, in MPB turbidity and parietal ring has been recorded, while in Endo medium violet microbial colonies with smooth edges and metallic luster has been disclosed (Figures 10, 11).

The internal organs, blood, lymphatic nodes and bone marrow of the dissected young ostriches have been subjected to microscopic and microbiological examination.

The mice infected with the suspender $(2 \mathrm{bln} / 1 \mathrm{ml})$ prepared from the 24-hour microbial cultivar of Salmonellosis through intra-abdominal method have recorded $83.3 \%$ lethality, while their internal organs have been subjected to morphological and physiological modifications.

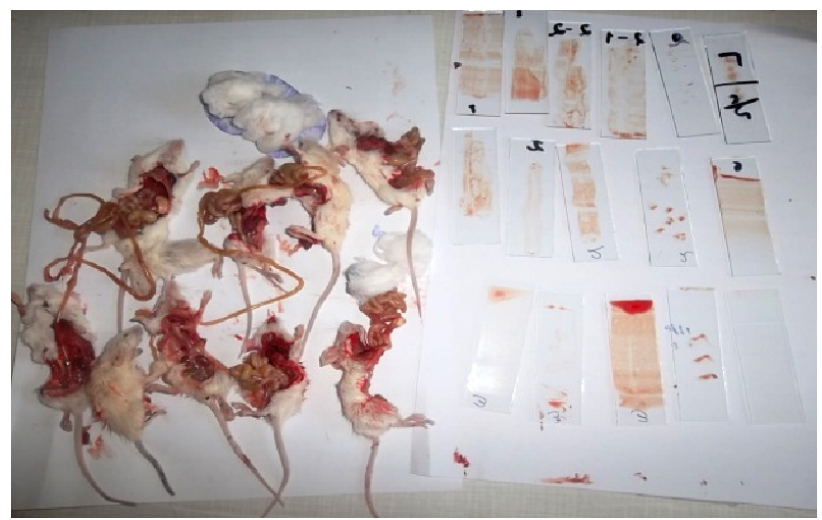

Figure 9. Salmonella-affected mice.

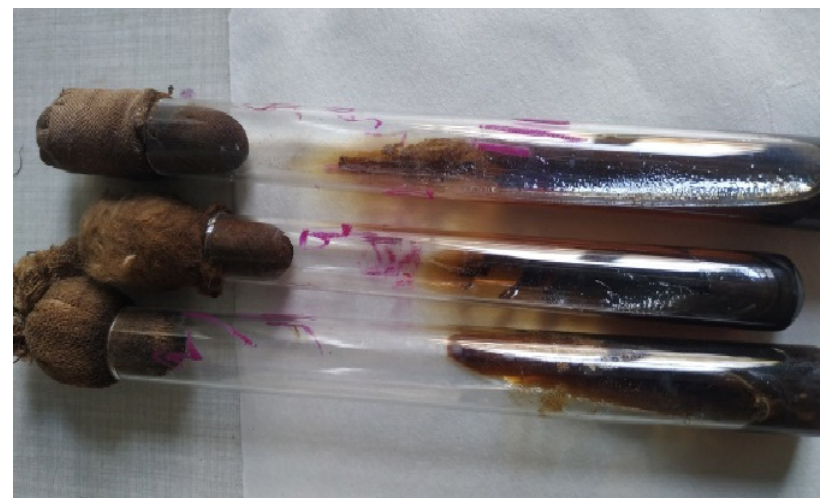

Figure 10. Salmonella growth in Bismuth-Sulphite nutrient medium. 


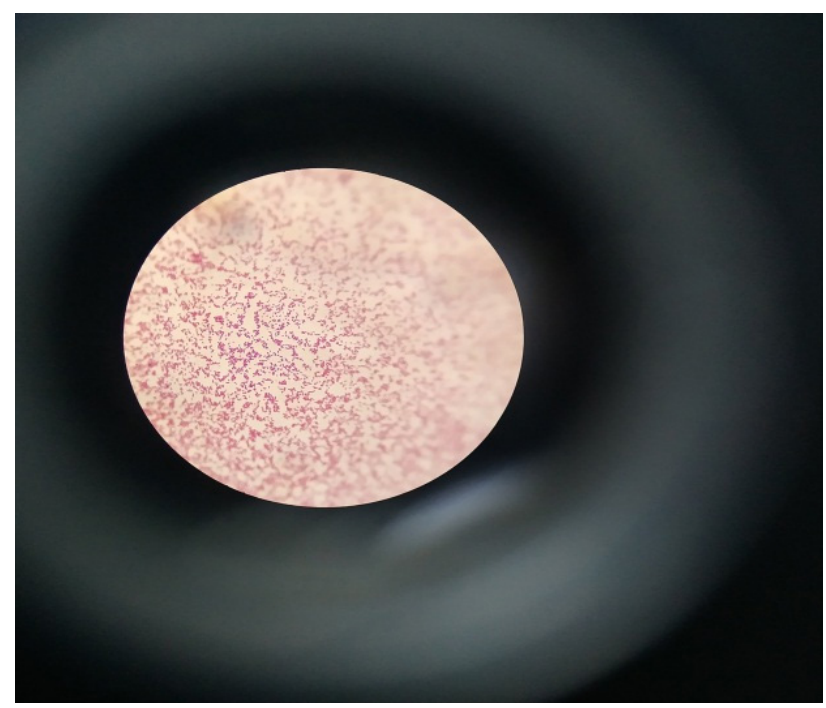

Figure 11. Microscopic image of Salmonellas.

Permanently virulent salmonella strains have been isolated from the internal organs of the experimental mice (Figure 9). During the investigations 42-day incubated eggs and those intended for hatching have been examined to disclose the salmonella carrier state of ostriches (Figures 2, 3).

For bacteriological research eggs weighing 1700-2200 g were selected on the bases of similarity. Seeding from the egg shell surface, subshell membrane, egg white and yolk content, as well as from the organs of suffocated chicks was implemented in the abovementioned mediums. Then the platings were kept at $36-37^{\circ} \mathrm{C}$ for $24-48$ hours (Figures 12, 13).

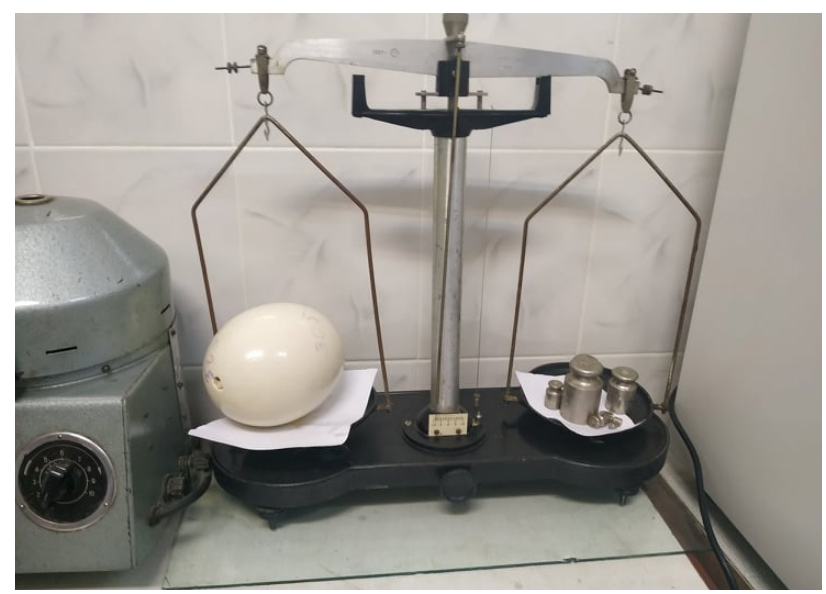

Figure 12. Determination of egg weight.

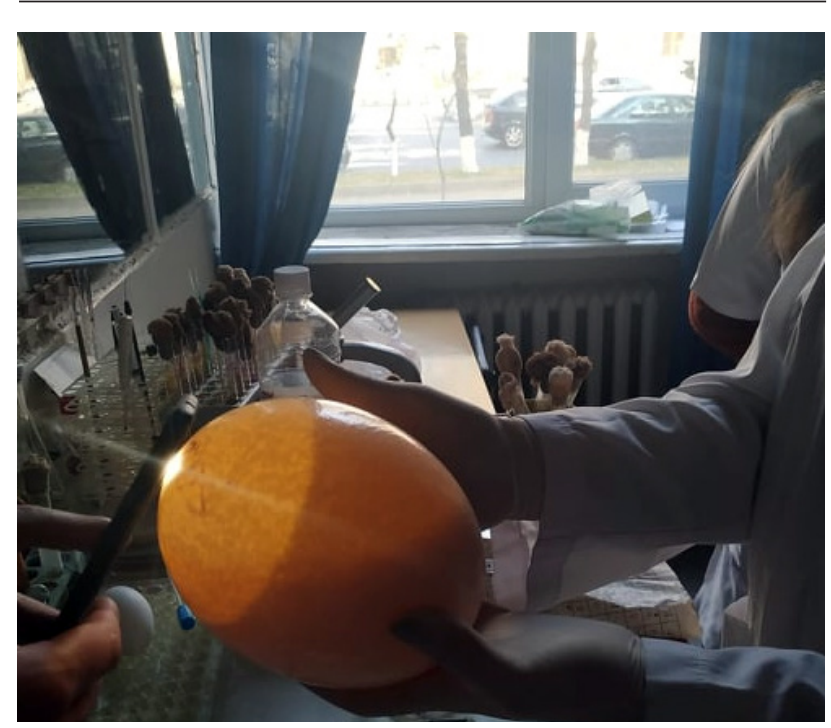

Figure 13. Incubated egg.

So, the presence of salmonellas was evaluated per the microbiological and microscopic investigations. It should be mentioned that Salmonella carrier state made 95-85\% in the clinically healthy ostriches aging 3-9 months, while in those of 3-6 years old it was $75 \%$. The highest index (95\%) of infectivity was recorded in 3-month old ostrich chicks.

A number of researchers distinctly report that the factors affecting the motility function of gastro-intestinal tract and gastric juice extraction are considered to be predisposing conditions for the mentioned infection (Bakulov, et al., 1984). This is often due to the abrupt change in the quality of the grain feed and its contamination with enterobacteria. In the result of microbiological examination conducted for the ostrich feed samples, a Salmonella growing tendency in the Bismuth-Sulphite Agar and Endo mediums has been also detected, while the lethality of mice infected with their microbial cultivars has made $66.6 \%$.

The results of microbiological investigations have shown that in the samples (internal organs, feces, egg, incubated egg) taken from the Masis ostrich breeding farms in the Ararat region Salmonella strains have been detected.

In order to retard intensive pathological changes in the bacilli carrier organisms it has been recommended to apply oxytetracycline belonging to the macrolide group of antibiotics, as well as sulfanilamide and furazolidone preparations in combined and individual forms (Grigoryan, 2002, Foley, et al., 2008).

For the disease prevention each chick was given 
oxytetracycline and sulfadimethoxine together with the drinking water for 5-7 days, while furazolidone was administered via feedstuff with $30 \mathrm{mg} / \mathrm{kg}$ dosage. To increase the body reactivity, minerals, vitaminized feed supplements and digestion-improving drugs were added to feed ration (Figure 14).

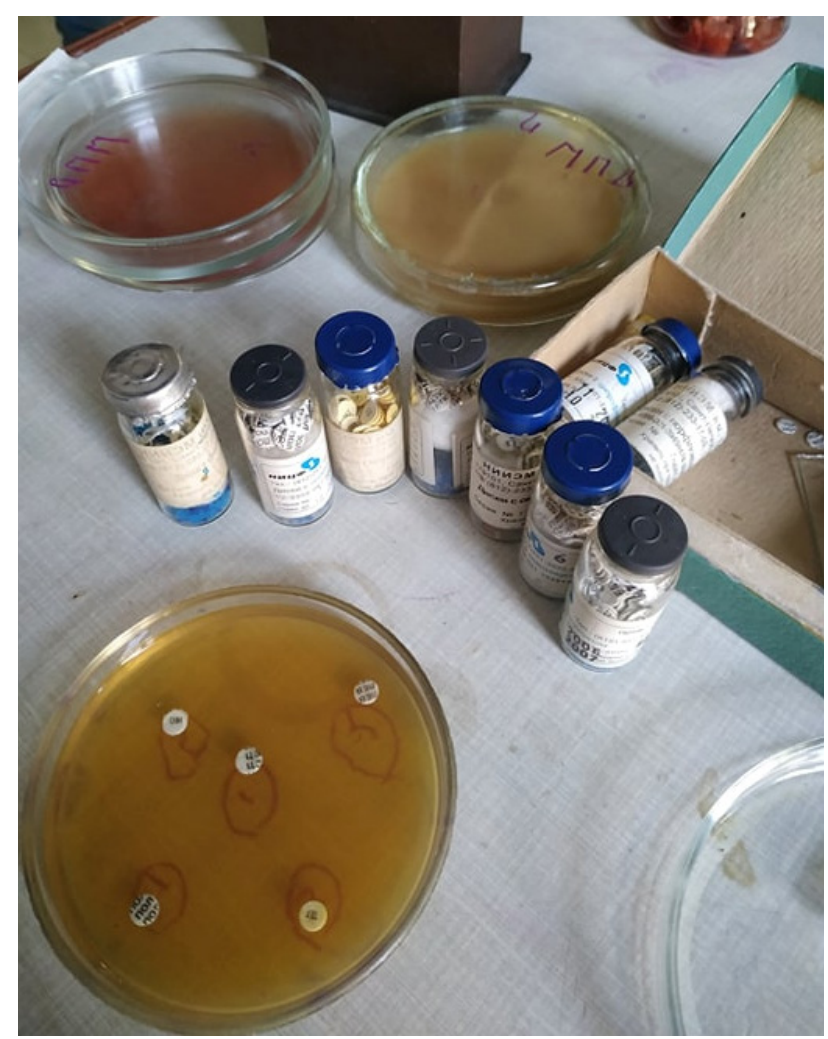

Figure 14. Antibiotic test.

During the treatment qualitative and quantitative changes in the blood formed elements of the birds were determined. The disclosure of Salmonellosis symptoms is of ultimate significance for taking adequate preventive and struggling measures against the infection (Grigoryan, 2002, 2005).

Epizootological analyses for the infection, death and lethality rate were conducted considering multiple vulnerable issues peculiar to the ostrich breeding farms. The research results were subjected to statistical and comparative analyses using the relevant methodology (Grigoryan, 2005).

Thus, out of 75 ostriches 15 were infected with Salmonellosis, 8 of which died, which accounts for 0.2 (20\%) death and 0.53 (53\%) lethality rate, respectively. In addition, the economic loss caused by the Salmonella carrier state was estimated through the following well- known formula:

$$
E l=D_{o} \times C-A l=8 \times 80000-0=640000 A M D,
$$

where $E l$ is the economic loss, $D_{o}$ is the number of dead ostriches (8), $C$ is the cost of an ostrich (8000 AMD) and $A l$ is the actual loss.

The estimation results showed that the economic loss in the ostrich breeding farm totally made 640000 AMD.

\section{Conclusion}

The salmonella carrier state of ostriches and their epizootological conditions have been studied and analyzed for the first time in Armenia. Salmonellas have been detected in the feedstuff, internal organs, blood, eggs and feces of the dead ostriches. Stress, displacement, Salmonella carrier state, rodents, Salmonella-contaminated feed, water and zoo-hygienic conditions can be among the multiple causes of Salmonella disease and mortality of ostriches.

So, for preventive-care measures it is recommended, first, to strongly observe zoo-hygienic conditions, then to add vitamins and minerals, as well as some antibiotics with sulfanilamide preparation in the feed ration.

\section{References}

1. Akbarmehr, J. (2010). Isolation of Salmonella spp. from Poultry (Ostrich, Pigeon and Chicken) and Detection of their HilA Gene by PCR Method // African Journal of Microbiology Research, - V. 4 (24), - pp. 2678-2681.

2. Antonov, B.I., Borisova, V.V., Volkova, P.M. (1986). Laboratory Research in Veterinary Medicine / Bacterial Infections: Guideline. - M.: Agropromizdat, - 352 p. (in Russian).

3. Antonov, V.Ya., Blinov, P.N. (1971). Laboratory Research in Veterinary Medicine. - M.: Kolos, - 647 p. (in Russian).

4. Babich, M.A. (1963). Nutrient Media / In the Book: Veterinary Laboratory Practice. - M.: Publishing House of Agricultural Literature. - V. 1, - pp. 47-61 (in Russian).

5. Bakulov, I.A., Glushkov, A.A., Nuykin, Ya.V. (1984). Basics of Epizootological Research / In the Book: Epizootology and Infectious Diseases of Agricultural Animals / Under the Editorship of A.A. Konopatkina. - M.: Kolos, - pp. 60-73 (in Russian).

6. Bakulov, I.A. (1987). Epizootology with Microbiology. - M.: Agropromizdat, - 415 p. (in Russian). 
7. Bakulov, I.A., Vedernikov, V.A., Semenikhin, A.L. (1997). Epizootology with Microbiology. - M.: Publishing House "Kolos", - 480 p. (in Russian).

8. Bakulov, I.A., Yurkov, G.G., Vedernikov, V.A., Orlov, F.M. (1986). Epizootological Dictionary: Guideline M.: Rosselkhozizdat, - 188 p. (in Russian).

9. Bessarabov, B.F. (1989). Poultry Diseases in the Developing Countries. Moscow, - pp. 52-53 (in Russian).

10. Bessarabov, B.F., Vatunin, A.A., Voronin, E.S. (2007). Infectious Diseases of Animals / Under the Editorship of A.A. Sidorchuk. - M.: Kolos, - 671 p. (in Russian).

11. Borisovich, Yu.F., Kirilov, L.V. (1981). Veterinary Drugs: Guideline / Under the Editorship of D.F. Osidze. - M.: Kolos, - 448 p. (in Russian).

12. Foley, S., Lynne, A., Nayak, R. (2008). Salmonella Challenges: Prevalence in Swine and Poultry and Potential Pathogenicity of Such Isolates // J. Anim. Sci., - V. 86, - pp. 149-162.

13. Grigoryan, S.L. (2002). Epizootology of Farm Animals and Infectious Diseases, "Astghik" Publishing House, Yerevan, - 641 p. (in Armenian).

14. Grigoryan, S.L. (2005). Labor Organization in Veterinary Medicine and Economics, - Yerevan, ASAU, - 287 p.
15. Grigoryan, S.L., Sarkisyan, M.A., Mkrtchyan, A.R. (2012). Dissemenation of Salmonellas in the Organism of Animals // Annals of Agrarian Science, - V. 10, - N 1, - pp. 79-80.

16. Konopatkin, A.A., Glushkov, A.A., Medvedev, S.S. (1984). Infectious Diseases of Agricultural Animals in Tropical Countries. - M.: Kolos, - 544 p. (in Russian).

17. Kudryashov, A.A., Svyatkovskiy, A.V. (2007). Infectious Diseases of Animals. - St. Petersburg. Moscow. Krasnodar, - 607 p. (in Russian).

18. Lysak, V.V. (2007). Microbiology. Minsk, - pp. 336338 (in Rusian).

19. Nurazyan, A.G. (1988). Milk and Dairy Product Microbiology and Bacteriological Research Methods. Yerevan, - pp. 190-196 (in Armenian).

20. Salautin, V.V. (1989). Pathomorphology and Differential Diagnostics of Pullorosis in Birds. Moscow, - pp. 16-18 (in Russian).

21. Sargsyan, M.A., Grigoryan, S.L. (2008). Prevalence of Pigeon Salmonellosis in Yerevan // Agriscience, - V. 7-8, - pp. 357-359.

22. Syurin, V.N., Belousova, R.V., Fomina, N.V. (1984). Veterinary Virology. - M.: Kolos, - 376 p. (in Russian).

23. Tarlamazyan, A., Hambardzumyan, L. (2004). Ostrich Breeding, Yerevan, - 199 p. (in Armenian). 